\title{
Fetomaternal Outcome After Induction of Labor at Term in Patients with Gestational Diabetes
}

\section{Sajida Imran, ${ }^{1}$ Asifa Noreen, ${ }^{2}$ Irum Khayam, ${ }^{3}$ Ayesha Arjmand, ${ }^{4}$ Razia Ghafoor, ${ }^{5}$ Fouzia Khalique $^{6}$}

\begin{abstract}
Objective: The objective of study is to determine the fetomaternal outcome after induction of labour at term in patients with gestational diabetes.

Methods: This study was conducted at department of Obstetrics and gynecology of Hameed Latif hospital, Lahore, Pakistan from March 2019 to October 2019. Seventy-nine pregnant women with gestational diabetes at term, undergoing induction of labour were included in the study after informed consent. Maternal outcome was studied by classifying different modes of delivery. Fetal outcome was measured on basis of APGAR scores and neonatal weight.

Results: There were 55/79 vaginal deliveries making vaginal delivery rate to be $66.9 \%$. Mean birth weight of neonates was $3.15+0.558 \mathrm{~kg}$. Mean APGAR Score at $1 \mathrm{~min}$ and 5 minutes were $7.7+0.6193$ and $8.8+$ 0.4793 respectively.

Conclusion: Labor induction in patients with gestational diabetes is associated with lower rate of cesarean delivery with a satisfactory fetal outcome.

Key Words: Gestational diabetes, induction of labour, maternal outcome, fetal outcome How to cite: Imran S., Dr., Noreen. A, Khayam. I., Arjmand A., Ghafoor R., Khalique F. Fetomaternal Outcome After Induction of Labor at Term in Patients with Gestational Diabetes. Esculapio 2021;17(01):49-54

DOI: https://doi.org/10.51273/esc21.2517110
\end{abstract}

\section{Introduction}

$\mathrm{G}^{\mathrm{s}}$ estational diabetes mellitus is defined as a glucose tolerance disorder that manifests itself during pregnancy, is characterized by glucose levels that are above normal but below that diagnostic of diabetes and poses unique diabetes-related risks to both the mother and the unborn baby. ${ }^{1}$

Gestational diabetes occurs in about $7-10 \%$ of pregnancies worldwide although the occurrence varies based upon its set criteria and the demographics of the population. ${ }^{2}$ In Pakistan alone, a developing country, the prevalence of gestational diabetes was found to be between $3-4 \%$ as shown by research conducted in specific areas of the country. ${ }^{3}$ The prevalence of ges-

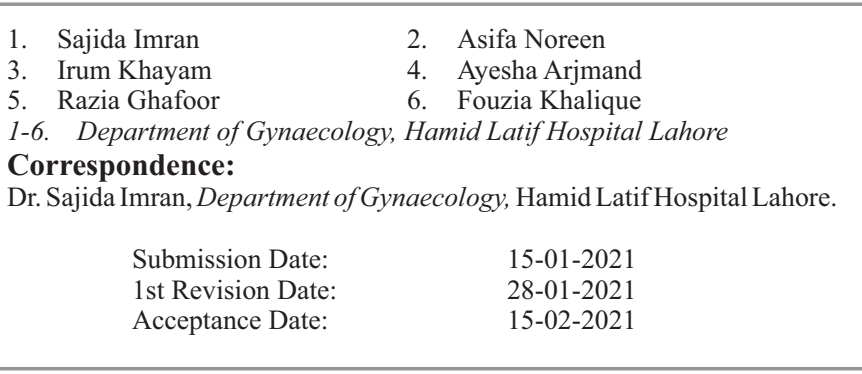

tational diabetes is directly proportional to the prevalence of type II Diabetes Mellitus in a population as well as the ethnic group, as research has shown that African, Hispanic, Indian, Pakistani and Asian women are more likely to develop gestational diabetes than Caucasian women of the same age. ${ }^{4}$ It's prevalence has seen to increase by nearly $30 \%$ in the past two decades especially in the developing countries as these countries are now being targeted by type II diabetes and its associated comorbidities. The increase in type II diabetes and its onset at a younger age can be well attributed to urbanization and sedentary lifestyles leading to significant obesity and insulin resistance in the populations. ${ }^{5}$

Gestational diabetes is associated with an increased risk of complications related to pregnancy and childbirth in both the mother and the baby. Gestational diabetes increases the risk of maternal complications like diabetic retinopathy, nephropathy and ketoacidosis and increases the likelihood of the mother developing full-blown type II diabetes mellitus later on in life. ${ }^{6}$ There are associated obstetric complications as well, including hypertensive disorders, cesarean deli- 
very, preterm birth, shoulder dystocia and slow labor. ${ }^{7}$ Perinatal complications include macrosomia, delayed intrauterine fetal development and respiratory distress. ${ }^{8}$ Gestational diabetes also causes neonatal complications like hypoglycemia, hypocalcemia, hyperbilirubinemia and polycythemia. One of its long term effects is the offspring being at risk for developing type II diabetes in early adulthood. ${ }^{9}$

Labor induction is a valuable and important obstetrical procedure. It is performed when prolongation of pregnancy is considered unsuitable for both maternal and fetal well-being. ${ }^{10}$ Mechanical methods of labor induction include the use of intracervical Foley's catheter and laminaria tents. Medical methods including oxytocin, prostaglandin and combinations of both. Cervical status and parity of the patient are two important factors that determine the outcome of labor induction. ${ }^{11}$ Labor induction may lead to certain complications like failed induction, uterine hyper stimulation, fetal distress, abruptio placentae, uterine rupture, inadvertent preterm delivery, hyponatremia, hyperbilirubinemia, hypotonic uterus and postpartum hemorrhage. Hence it is important to assess the effects of induction on labor itself especially in patients with gestational diabetes to prevent added complications.

Timely detection and initiation of treatment is essential to prevent complications caused by gestational diabetes. ${ }^{8}$ Appropriate clinical management is that which is customized according to the patient's condition, is timed appropriately with no delay and carried out considering the woman's consent and informed decisions. This is vital especially in a country like Pakistan where the disease goes mostly unnoticed with no significant data regarding the prevalence of gestational diabetes and development of preventative strategies. Complication rates are higher in Pakistan due to poor glycemic control.' This study was conducted at Hameed Latif Hospital, a tertiary care hospital in the metropolitan city of Lahore, Pakistan. It aims to assess the maternofetal outcomes in women with a history of gestational diabetes undergoing induction of labor to better understand the comorbidities associated with gestational diabetes at term and form a base for preventative and curative measures against it.

\section{Methods}

This cohort study was conducted at the Obstetrics and Gynecology department of Hameed Latif Hospital,
Lahore from March 2019 to October 2019. It was a prospective study which included both outdoor (OPD) and admitted pregnant patients. The patients were either attending antenatal OPD or medicine OPD or were admitted in the medicine or obstetric wards.

The inclusion criteria comprised known cases of gestational diabetes with no contraindications for vaginal delivery. The criteria for gestational diabetes was set as fasting sugar level of greater than 100 $\mathrm{mg} / \mathrm{dL}$ and post-prandial sugar level of greater than $140 \mathrm{mg} / \mathrm{dL}$ during pregnancy. The exclusion criteria comprised known diabetics i.e. those with diabetes outside of pregnancy and those with history of previous uterine surgery.

Seventy-nine women pregnant patients with diagnosed gestational diabetes in whom labor was induced participated in the study. Labor was induced using tablets after measuring Bishop score and getting a score of 6 . The women were between 15-40 years of age, primigravida as well as multigravida and their gestational age varied between 38-40 weeks.

Sampling technique used was non randomized purposive sampling. Informed consent was taken from the participants while keeping their identity anonymous and confidential. Information was collected after getting ethical approval for research from the participants via a detailed proforma. Proforma consisted of information regarding demographics, patient history, examination, investigations, labor induction, maternal and fetal outcome.

The results were analyzed using SPSS software version 23. The continuous variables were presented via frequency, mean and standard deviation. The categorical data was presented as frequency and percentages.

\section{Results}

Data was collected via proforma from 79 patients having gestational diabetes in whom labor was inducted to study the maternofetal outcome. Majority of the patients $(74.6 \%)$ were aged between 21 and 30 years. Mean age calculated was $25 \pm 5.0252$. Most of the patients $(58.2 \%, 46 / 79)$ were with their first pregnancy. Each patients' gestational age was also tabulated as 36 weeks onwards. $41.8 \%$ of the patients were at gestational age of 39 to $39+6$ weeks, which makes about 33 patients out of 79 included in this group. Next most common gestational ages were $38-38+6$ weeks $(26.6 \%, 21 / 79)$ and 40 weeks or more $(19 \%$, 
$15 / 79)$ respectively. Gestational ages of $37-37+6$ weeks $(8.9 \%, 7 / 79)$ and $36-36+6$ weeks $(3.8 \%, 3 / 79)$ were less common than the rest. Mean gestational age was $39+1$, with standard deviation calculated to be 1.0085.( Table 1)

Maternal outcome was assessed by grouping into spontaneous/operative vaginal delivery and lower segment cesarean section (LSCS). (Table 2 ). 55/79 $(69.6 \%)$ patients had vaginal delivery out of which total 6 cases $(7.6 \%)$ of spontaneous vaginal delivery. Operative vaginal delivery was further classified into Ventouse and Forceps. Ventouse delivery comprised nearly half of the cases at $54.4 \%$, with 43 cases out of 79. Forceps delivery had the same percentage as spontaneous vaginal delivery $(7.6 \%)$ with total 6 cases only. Lower segment cesarean section was

Table 1: Sociodemographic Characteristics of Participants $(n=79)$

\begin{tabular}{|c|c|c|c|c|c|}
\hline $\begin{array}{l}\text { S/ } \\
\text { No. }\end{array}$ & $\begin{array}{c}\text { Sociodemographic } \\
\text { Characteristics }\end{array}$ & $\begin{array}{l}\text { No. of } \\
\text { cases }\end{array}$ & $\begin{array}{l}\text { Percen- } \\
\text { tage }\end{array}$ & Mean & $\begin{array}{l}\text { Standard } \\
\text { Deviation }\end{array}$ \\
\hline \multirow[t]{4}{*}{1.} & Age in years & & & \multirow{4}{*}{25} & \multirow{4}{*}{5.0252} \\
\hline & a. Up to 20 & 9 & 11.39 & & \\
\hline & b. $21-30$ & 59 & 74.68 & & \\
\hline & c. 31 and above & 11 & 13.92 & & \\
\hline \multirow[t]{5}{*}{2.} & Gravidity & & & \multirow{5}{*}{---} & \multirow{5}{*}{---} \\
\hline & a. Primigravida & 46 & 58.23 & & \\
\hline & b. Gravida 2 & 22 & 27.85 & & \\
\hline & c. Gravida 3 & 7 & 8.86 & & \\
\hline & d. Gravida 4 or more & 4 & 5.06 & & \\
\hline \multirow[t]{6}{*}{3.} & Gestational Age & & & \multirow{6}{*}{$39+1$} & \multirow{6}{*}{1.0085} \\
\hline & a. $36-36+6$ weeks & 3 & 3.79 & & \\
\hline & b. $37-37+6$ weeks & 7 & 8.86 & & \\
\hline & c. $38-38+6$ weeks & 21 & 26.58 & & \\
\hline & d. $39-39+6$ weeks & 33 & 41.77 & & \\
\hline & e. 40 weeks or more & 15 & 18.99 & & \\
\hline
\end{tabular}

second to Ventouse only in terms of number of cases at $30.4 \%$ i.e. 24 cases out of the 79 . The indications for LSCS were grouped into failed induction, fetal distress, both or failed progress of labor. (Table 3 ). The commonest indication was failed induction of labor with $14 / 24$ cases $(58.3 \%)$. Fetal distress was second in terms of occurrence, with 8/24 cases (33.3\%).

Fetal outcome was assessed by neonatal weight in kilograms and Apgar score at 1 minute and 5 minutes after birth respectively. The greatest proportion of neonates weighed between 3.1 to 3.5 kilograms (39.2\%, $31 / 79$ ) followed by the range of 2.6 to 3.0 kilograms (31.6\%, 25/79), 3.6 to 4.0 kilograms $(20.3 \%, 16 / 79)$, 2.1 to 2.5 kilograms $(5 \%, 4 / 79), 2$ or less than 2 kilograms $(2.5 \%, 2 / 79)$ and 4.1 kilograms and above $(1.3 \%, 1 / 79)$, respectively. Thus, the results showed that most of the neonates weighed between the range of $3.1-3.5 \mathrm{~kg}$ and $2.6-3.0 \mathrm{~kg}$ whereas the extremes of Table 2: Maternal Outcome $(n=79)$

\begin{tabular}{llcc}
\hline $\begin{array}{c}\text { S/ } \\
\text { No. }\end{array}$ & \multicolumn{1}{c}{ Maternal Outcome } & $\begin{array}{c}\text { No. of } \\
\text { Cases }\end{array}$ & $\begin{array}{c}\text { Percen- } \\
\text { tage }\end{array}$ \\
\hline 1. & Spontaneous vaginal delivery & 6 & 7.59 \\
2. & $\begin{array}{l}\text { Operative vaginal delivery } \\
\text { a. Ventouse }\end{array}$ & 43 & 54.43 \\
& $\quad$ b. Forceps & 6 & 7.59 \\
3. & Lower segment cesarean section & 24 & 30.38 \\
\hline
\end{tabular}

Table 3: Indication for Induction of Emergency LSCS $(n=24)$

\begin{tabular}{llcc}
\hline $\begin{array}{c}\text { S/ } \\
\text { No. }\end{array}$ & \multicolumn{1}{c}{ Indication } & $\begin{array}{c}\text { No. of } \\
\text { Cases }\end{array}$ & $\begin{array}{c}\text { Percen- } \\
\text { tage }\end{array}$ \\
\hline 1. & Failed induction of Labor & 14 & 58.33 \\
2. & Fetal distress & 8 & 33.33 \\
3. & Both above & 1 & 4.17 \\
4. & Failed progress & 1 & 4.17 \\
\hline
\end{tabular}

weight such as less than $2 \mathrm{~kg}$ and greater than 4 were $\mathrm{kg}$ demonstrated by very few (1-2) cases only. Mean weight was $3.15 \pm 0.5582 \mathrm{~kg}$.

Apgar score was calculated a 1 minute and 5 minutes of birth respectively. At 1 minute, $76 \%$ or around three quarters of neonates scored 8 with $60 / 79$ cases. $15.2 \%$ of neonates had an Apgar score of 7(12/79), 7.6\% had an Apgar score of 6 or less than $6(6 / 79)$ and $1.3 \%$ of neonates had an Apgar score of 9 (1/79). None of the neonates scored 10 at 1 minute. Thus, the lowest score was 6 or less than 6 and the highest was 9. Compared to this, the lowest Apgar score at 5 minutes was 7 and the highest was 10 . These two extreme scores were not demonstrated by many cases as only $2 / 79$ neonates $(2.5 \%)$ and $1 / 79$ neonates $(1.3 \%)$ scored 7 and 10 respectively. $81 \%$ of the neonates demonstrated a score of 9 , with $64 / 79$ such cases. Next to this, $15.2 \%$ neonates scored 8 , with a total of $12 / 79$ cases. Thus, the most common Apgar score was 8 at 1 minute and 9 at 5 minutes. Mean score at 1 minute was $7.7 \pm 0.6193$. Mean score at 5 minutes was $8.8 \pm 0.4793$.( Table 4 )

\section{Discussion}

This study was carried out at a teaching hospital to reveal and analyze the maternal and fetal outcomes in women with gestational diabetes who underwent labor induction. 79 known cases of gestational diabetes were used for this study.

In this study, maximum patients $(75 \%)$ were clustered 
Table 4: Fetal Outcome $(n=79)$

\begin{tabular}{|c|c|c|c|c|c|}
\hline $\begin{array}{c}\text { S/ } \\
\text { No. }\end{array}$ & Fetal Outcome & $\begin{array}{l}\text { No. of } \\
\text { Cases }\end{array}$ & $\begin{array}{c}\text { Percen- } \\
\text { tage }\end{array}$ & Mean & $\begin{array}{l}\text { Standard } \\
\text { Deviation }\end{array}$ \\
\hline \multirow[t]{7}{*}{1.} & \multicolumn{5}{|l|}{ Neonatal Weight/kg } \\
\hline & a. 2 or less than 2 & 2 & 2.53 & 3.15 & 0.5582 \\
\hline & b. $2.1-2.5$ & 4 & 5.06 & & \\
\hline & c. $2.6-3.0$ & 25 & 31.64 & & \\
\hline & d. $\quad 3.1-3.5$ & 31 & 39.24 & & \\
\hline & e. $\quad 3.6-4.0$ & 16 & 20.25 & & \\
\hline & f. 4.1 and above & 1 & 1.26 & & \\
\hline \multirow[t]{13}{*}{2.} & Apgar score & & & & \\
\hline & a. $1 \mathrm{~min}$ & & & & \\
\hline & 6 or less than 6 & 6 & 7.59 & 7.7 & 0.6193 \\
\hline & 7 & 12 & 15.19 & & \\
\hline & 8 & 60 & 75.95 & & \\
\hline & 9 & 1 & 1.26 & & \\
\hline & 10 & 0 & 0 & & \\
\hline & b. $5 \mathrm{~min}$ & & & & \\
\hline & 6 or less than 6 & 0 & 0 & 8.8 & 0.4793 \\
\hline & 7 & 2 & 2.53 & & \\
\hline & 8 & 12 & 15.19 & & \\
\hline & 9 & 64 & 81.01 & & \\
\hline & 10 & 1 & 1.26 & & \\
\hline
\end{tabular}

in the age group of 21-30 years. This is in contrast with a study conducted in Jammu that unveiled an association between increasing age and gestational diabetes, thus inferring that women with normal glucose tolerance tests tend to be younger and those with gestational diabetes, older. ${ }^{12}$ More than half of the patients $(58.2 \%)$ were primigravida while the rest of the patients $(41.8 \%)$ were multigravida. Although in a study advanced age, high BMI and family history of diabetes were seen as important risk factors for gestational diabetes, no significant correlation existed between gestational diabetes and parity, frequency and number of pregnancies and number of live births. ${ }^{13}$

Maternal outcome was studied by classifying different modes of delivery. The study showed that around 30 percent of the patients under study underwent Lower Segment Cesarean Section, making it the second most common mode of birth or maternal outcome. The most common maternal outcome was birth via operative vaginal delivery, with Ventouse method being 54.4 percent of the outcome and forceps delivery 7.6 percent of the outcome. A study conducted to assess the effects of a policy of labor induction at or beyond term compared with a policy of awaiting spontaneous labor on pregnancy outcomes on mother and children using randomized control trials (RCT) concluded that labor induction is associated with fewer perinatal deaths and cesarean sections but more operative vaginal births, the latter reinforcing the results of our study. ${ }^{14}$ Observational studies carried out to assess maternal and fetal outcome following induction of labor showed that women with elective induction of labor had a higher odd of cesarean delivery compared to women with spontaneous labor. ${ }^{15}$ Two studies showed considerable differences in the outcome of cesarean delivery between women who had elective induction and those who underwent expectant management. In both the studies the percentages of cesarean section following induction were less than that concluded by our study i.e. 30 percent. ${ }^{16,17}$ Another study conducted in Southern India revealed that 32 percent of women with gestational diabetes under study had undergone cesarean deliveries. ${ }^{(18)}$ Higher risk for cesarean section have been reported from other studies. ${ }^{19,20}$

Fetal outcome was assessed in terms of neonatal birth weight and Apgar scores at 1 minute and 5 minutes after birth. Most neonates in our study weighed between $3.1-3.5 \mathrm{~kg}(39.2 \%)$, followed by $2.6-3.0 \mathrm{~kg}$ $(31.6 \%)$ and $3.6-4.0 \mathrm{~kg}(21.3 \%)$. Macrosomia is one of the adverse neonatal outcomes of gestational diabetes. Some studies report that $15-45 \%$ of newborns of women with gestational diabetes have macrosomia. ${ }^{21,22}$ The mean weight calculated in our study was $3.15 \mathrm{~kg}$. The reason may be meticulous control of blood sugar levels which corelates to macrosomia. Mean gestational age at delivery in our patients was $39 \pm 1$ weeks of gestation. Gestational age at induction is important in determining outcome in terms of weight of baby. Studies regarding induction of labor at 38 to 39 weeks of gestation have shown a decrease while those at or beyond 40 weeks of gestation show increased chances of macrosomia. ${ }^{21,22.23}$

Mean scores at $1 \mathrm{~min}$ and 5 mins were 7.7 and 8.8 respectively in our study. A study aimed at finding an association between gestational diabetes and Apgar scores of full-term neonates, with mean Apgar scores at $1 \mathrm{~min}$ and $5 \mathrm{~min}$ of 7.8 and 8.9 respectively, concluded that maternal history of gestational diabetes does not appear to be associated with the 1-minute and 5minute Apgar scores of full-term newborns of mothers with gestational diabetes as compared to newborns of mothers without a history of impaired glucose tolerance. ${ }^{24}$ When compared to babies born to mothers without gestational diabetes, those born to mothers with it were at higher risk of having a lower fiveminute APGAR score. In our study only 7.6 percent of newborns had low APGAR score at 1 minute and 
none had low APGAR score at 5 minutes. In a study regarding neonatal outcomes according to different therapies for gestational diabetes, 5.6 percent had low Apgar score at the first minute and 1.1 percent had low Apgar score at the fifth minute. Thus, this study concluded that there was no risk of low Apgar at either first or fifth minute in newborns of women with gestational diabetes. ${ }^{25}$

Our study had its limitations like only one parameter i.e. mode of delivery was used to assess maternal outcome whereas other parameters like maternal weight, body-max index and presence of preeclampsia and eclampsia were not studied. It is cross sectional study, a comparative study of induction of labour with nondiabetic patients should be planned. The association between maternal outcome and gestational age also requires more attention to know exactly the incidence rates of cesarean (or other modes of deliveries) at specific gestational ages.

\section{Conclusion}

The incidence of cesarean delivery in women with gestational diabetes who have undergone induction of labor is low in our study along with satisfactory fetal outcome in terms of birth weight and APGAR score. Proper selection of patients, adequate diabetic control and induction at 39 weeks leads to successful outcome.

\section{Conflict of Interest: $\quad$ None}

\section{References}

1. Hutcheon JA, Lisonkova S, Joseph KS. Epidemiology of pre-eclampsia and the other hypertensive disorders of pregnancy. Vol. 25, Best Practice and Research: Clinical Obstetrics and Gynaecology. 2011.p. 391-403.

2. Belay AS, Wudad T. Prevalence and associated factors of pre-eclampsia among pregnant women attending anti-natal care at Mettu Karl referal hospital, Ethiopia: cross-sectional study. Clin Hypertens. 2019; 25(1): 14.

3. Gupta Y, Kalra B. Screening and diagnosis of gestational diabetes mellitus. Vol. 66, JPMA. The Journal of the Pakistan Medical Association. 2016. p. S19-21.

4. Riaz M, Nawaz A, Masood SN, Fawwad A, Basit A, Shera AS. Frequency of gestational diabetes mellitus using DIPSI criteria, a study from Pakistan. Clin Epidemiol Glob Heal. 2019;7(2):218-21.

5. Tahseen S, Qurban S, Mazher R, Sultana N, Mahmood
Z, Majeed T. Frequency of factors leading to gestational diabetes. Pakistan J Med Heal Sci. 2016; 10(1): 219-21.

6. Monteiro LJ, Norman JE, Rice GE, Illanes SE. Fetal programming and gestational diabetes mellitus. Placenta. 2016;48:S54-60.

7. Alberti KGMM, Zimmet PZ. Definition, diagnosis and classification of diabetes mellitus and its complications. Part 1: Diagnosis and classification of diabetes mellitus. Provisional report of a WHO consultation. Diabet Med. 1998;15(7):539-53.

8. Chiefari E, Arcidiacono B, Foti D, Brunetti A. Gestational diabetes mellitus: an updated overview. Vol. 40, Journal of Endocrinological Investigation. 2017.p. 899-909.

9. Langer O, Yogev Y, Most O, Xenakis EMJ. Gestational diabetes: The consequences of not treating. In: American Journal of Obstetrics and Gynecology. 2005.p. 989-97.

10. Ryan RM, McCarthy FP. Induction of labour. Vol. 29, Obstetrics, Gynaecology and Reproductive Medicine. 2019. p. 351-8.

11. Boyon C, Monsarrat N, Clouqueur E, Deruelle P. Maturation cervicale: $\mathrm{Y}$ a-t-il un avantage à utiliser un double ballonnet pour le déclenchement du travail ? Gynecol Obstet Fertil. 2014;42(10):674-80.

12. Wahi P, Dogra V, Jandial K, Bhagat R, Gupta R, Gupta S, et al. Prevalence of gestational diabetes mellitus (GDM) and its outcomes in Jammu region. J Assoc Physicians India. 2011;59(4):227-30.

13. Vilchez GA, Dai J, Hoyos LR, Gill N, Bahado-Singh R, Sokol RJ. Labor and neonatal outcomes after term induction of labor in gestational diabetes. J Perinatol. 2015;35(11):924-9.

14. Middleton P, Shepherd E, Crowther CA. Induction of labour for improving birth outcomes for women at or beyond term. Vol. 2018, Cochrane Database of Systematic Reviews. 2018.

15. Caughey AB, Sundaram V, Kaimal AJ, Cheng YW, Gienger A, Little SE, et al. Maternal and neonatal outcomes of elective induction of labor. Evidence report/technology assessment. 2009.p. 1-257.

16. Darney BG, Snowden JM, Cheng YW, Jacob L, Nicholson JM, Kaimal A, et al. Elective induction of labor at term compared with expectant management : Maternal and neonatal outcomes. Obstet Gynecol. 2013;122(4):761-9.

17. Melamed N, Ray JG, Geary M, Bedard D, Yang C, Sprague A, et al. Induction of labor before 40 weeks is associated with lower rate of cesarean delivery in women with gestational diabetes mellitus Presented 
at the 36th annual meeting of the Society for Maternal-Fetal Medicine, Atlanta, GA, February 1-6, 2016. Am J Obstet Gynecol. 2016;214(3):364.e1-364.e8.

18. Sreelakshmi P, Nair S, Soman B, Alex R, Vijayakumar K, Kutty Vr. Maternal and neonatal outcomes of gestational diabetes: A retrospective cohort study from Southern India. J Fam Med Prim Care. 2015; 4(3):395. 9

19. HAMEL MS, KOLE MB, ROUSE D, WERNER E. Labor Induction and Cesarean Delivery Risk in Women with Gestational Diabetes Mellitus. Diabetes. 2018 May;67(Supplement 1):1427-P.

20. Thiruvikrama Prakash G, Das AK, Habeebullah S, Bhat V, Shamanna SB. Maternal and neonatal outcome in mothers with gestational diabetes mellitus. Indian J Endocrinol Metab. 2017;21(6):854-8.

21. Kc K, Shakya S, Zhang H. Gestational diabetes mellitus and macrosomia: A literature review. Vol. 66, Annals of Nutrition and Metabolism. 2015. p. 14-20.

22. Yang Y, Wang Z, Mo M, Muyiduli X, Wang S, Li M, et al. The association of gestational diabetes mellitus with fetal birth weight. J Diabetes Complications. 2018; 32(7):635-42.
23. Lurie $\mathrm{S}$, Insler $\mathrm{V}$, Hagay $\mathrm{ZJ}$. Induction of labor at 38 to 39 weeks of gestation reduces the incidence of shoulder dystocia in gestational diabetic patients class A2. Am J Perinatol. 1996;13(5):293-6.

24. Yeagle KP, O’brien JM, Curtin WM, Ural SH. Are gestational and type ii diabetes mellitus associated with the apgar scores of full-term neonates? Int $\mathbf{J}$ Womens Health. 2018;10:603-7.

25. Silva AL da, Amaral AR do, Oliveira DS de, Martins L, e Silva MR, Silva JC. Neonatal outcomes according to different therapies for gestational diabetes mellitus. J Pediatr (Versão em Port. 2017; 93(1): 8793.

\section{Authors Contribution}

NF: Conceptionlization of Project

AL: Data Collection

IS,KF: Literature Search

IS: Statistical Analysis

AA: Drafting, Revision

IS,GT: Writing of Manuscript 